\title{
Short Communication: Isolation of Prototheca Species Strains from Environmental Sources in Dairy Herds
}

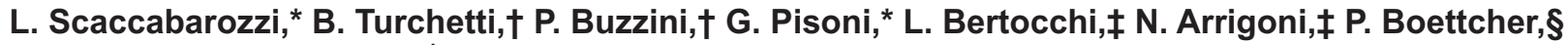 \\ V. Bronzo, ${ }^{*}$ and P. Moroni*1 \\ *Department of Veterinary Pathology, Hygiene and Public Health, University of Milan, via Celoria 10, 20133 Milan, Italy \\ †Department of Applied Biology-Microbiology, University of Perugia, 06100 Perugia, Italy \\ łlstituto Zooprofilattico Sperimentale of Lombardia and Emilia Romagna, 25100 Brescia, Italy \\ §Institute of Agricultural Biology and Biotechnology (IBBA), Consiglio Nazionale delle Ricerche (CNR), 20133 Milan, Italy
}

\begin{abstract}
Composite milk samples from 548 cows, and samples from feces, feed, bedding, water, liners (before and after milking), and the postdipping product were aseptically collected from 2 Italian dairy herds from February to November of 2006. Prototheca zopfii was isolated from $11.9 \%$ of milk samples, $15 \%$ of feces, and $33.3 \%$ of bedding samples. No viable cells of $P$. zopfii were observed in water before washing procedures, whereas 25 to $28.6 \%$ of samples from water used for washing both refrigeration tanks and milking equipment were contaminated with this yeast-like microalga. Analogously, the presence of $P$. zopfii was detected only on swabs collected from the liners after milking. Interestingly, in 1 of the 2 herds, water from the drinking trough was contaminated by viable cells of both $P$. zopfii and the related environmental species Prototheca stagnora. No viable cells were observed in cow feed. On the basis of the results presented herein, $P$. zopfii seemed to be widespread throughout the environments of dairy herds where outbreaks of bovine mastitis had occurred.
\end{abstract}

Key words: Prototheca spp., yeast-like microorganism, environmental source, dairy cow

The genus Prototheca includes unicellular yeast-like colorless microalgae (phylogenetically related to Chlorella) and comprises 4 accepted species (Prototheca zopfii, Prototheca stagnora, Prototheca whickeramii, and Prototheca ulmea) and a fifth not generally accepted species (Prototheca moriformis; Ueno et al., 2003). These microorganisms reproduce only asexually; the cytoplasm splits, forming 2 to 16 daughter cells. According to the current literature, Prototheca spp. strains are commonly associated with a variety of habitats, with a particular affinity for wet environments containing rotting organic matter (Pore, 1998).

Received February 22, 2008.

Accepted May 29, 2008.

${ }^{1}$ Corresponding author:paolo.moroni@unimi.it
Although infections caused by $P$. zopfii have been sporadically observed in dogs, mastitis in dairy cows represents the main form of occurrence of protothecosis in animals (Janosi et al., 2001). Because mammary gland infections caused by $P$. zopfii are rarely associated with clinical signs, the nondetection in dairy cows of subclinical mastitis can be a serious problem affecting the entire herd. Cattle appear to be equally susceptible to new infections, regardless of the stage of lactation, including the dry period (Furuoka et al., 1989). In cows, the infection may be restricted to the udder or disseminated to the lymph nodes (McDonald et al., 1984).

Outbreaks of bovine mastitis attributable to $P$. zopfii have been described as a global problem, with reported occurrences in North America (Anderson and Walker, 1988; Higgins and Larouche, 1989), South America (Almeraya, 1994; Castagna de Vargas et al., 1998), and Europe (Legneau, 1996; Aalbaek et al., 1998; Buzzini et al., 2004). Because of the lack of response of Prototheca spp. to most antibiotics (Segal et al., 1976; Casal and Gutierrez, 1983; Shahan and Pore, 1991), culling of infected cows is often recommended.

The common belief is that the transmission of an infection caused by $P$. zopfii occurs by means of direct (and constant) contact of mammary glands with other contaminated sources on the dairy farm. Only one study has been devoted so far to the exploration and characterization of environmental sources of Prototheca spp. in dairy herds (Costa et al., 1997). The aim of the present study was to evaluate the potential sources of $P$. zopfii during outbreaks by evaluating the distribution of the microorganism in samples collected from 2 dairy herd environments.

The 2 dairy herds had 490 (herd A) and 200 (herd B) total dairy cows, respectively, and were located in northern Italy. The study was undertaken during outbreaks of clinical mastitis caused by $P$. zopfii. The outbreaks were detected during the 2006 milking season. The milking routine in both herds included premilking teat cleaning with lactic acid (5\%), followed by drying 
Table 1. Management and milking routine description for herds A and B

\begin{tabular}{lll}
\hline Item & Herd A & Herd B \\
\hline Total animals, n & 490 & 200 \\
Housing & Free-stall barn with cubicle & Free-stall barn with cubicle \\
Type of bedding material & Straw & Sawdust \\
Frequency of changing bedding & 1 to 2 times a week & 2 to 3 times a week \\
Type of milking parlor & Rotary, 32 place & Herringbone, 12 + 12 place \\
Type of predipping & Lactic acid & Lactic acid \\
Type of postdipping & Dip iodine solution & Spray iodine solution \\
\hline
\end{tabular}

with a paper towel. Postmilking disinfection was done with an iodine-based dip solution in herd $\mathrm{A}$ and with an iodine-based spray in herd B. Management conditions (Table 1) in both herds were similar, except for the bedding material: the cubicles in herd A were bedded with straw, whereas those in herd B were bedded with sawdust.

Every month, the bulk tank SCC was measured by the local breeders association as a herd-level check for mastitis. At the end of each lactation, all cows were systematically administered a slow-release intramammary antibiotic preparation to treat chronic mastitis and prevent new infections during the dry period.

Both dairy herds were enrolled in a clinical mastitis monitoring program, managed by the regional breeding association (Associazone Provinciale Allevatori Milano and Modena, Italy), whereby milk from each cow was sampled once during the early-lactation period (5 to 70 DIM) for bacteriological and cytological analysis. During the period of this study (February to November 2006), composite samples were taken from 548 cows, or approximately 55 different cows per month. Before the morning milking, teat ends were swabbed with chlorhexidine. After discarding the first 3 streams, pooled milk samples were collected into sterile tubes. Samples were kept at $4^{\circ} \mathrm{C}$ and immediately transported to the laboratory for microbiological analysis. At the last visit (November), samples from the following different sites in the lactating and dry-cow environments of both herds were collected: cow drinking water (54 samples from the watering trough); cow feed (20 samples from the TMR); cow resting areas (12 samples from bedding material); cattle feces (20 from direct rectal sampling); milking apparatus (64 swabs samples collected from the same teat cup liners both before $(\mathrm{n}=32)$ and after milking $(\mathrm{n}=32)$ on the same day; 12 samples of washing water from the milk transport system before and after milking; water after refrigeration tank washing (4 samples); and 5 samples from the postdipping liquid. Samples from the watering trough and milking system wash water were collected into $50-\mathrm{mL}$ sterile tubes and immediately refrigerated. Grab samples from bedding, feces, and feed were collected in sterile sample bags, and a new pair of disposable gloves was used for each sample. Samples were stored in a cooler with ice packs and transported to the laboratory, where processing was initiated within a few hours of sample collection. Fecal samples were collected from the rectum of multiparous cows by using single-use palpation sleeves. To prevent cross-contamination, care was taken to avoid contact of the outside of the sleeve with anything but the sampled cow. Sleeves were turned inside out after sample collection and tied shut. Samples were transported to the laboratory in cooler boxes with ice packs. Fecal samples were stored at refrigeration temperature $\left(+4^{\circ} \mathrm{C}\right)$ or, if stored for more than $1 \mathrm{~d}$, were frozen $\left(-20^{\circ} \mathrm{C}\right)$.

All milk bacteriological procedures were performed according to the recommendations of the National Mastitis Council (1996). A 0.01-mL aliquot of each sample was plated onto 5\% sheep blood agar and Prototheca isolation medium (PIM; Pore, 1973) agar plates. Plates were incubated aerobically at $37^{\circ} \mathrm{C}$ and examined at 24,48 , and 72 h. For each milk sample, SCC was determined by an automated fluorescent microscopic somatic cell counter (Bentley Somacount 150, Bentley Instrument, Chaska, MN).

Prototheca spp. cells in swabs from teat cup liners were directly isolated by streaking on PIM agar dishes (Pore, 1998). Viable counts were performed by serial dilution and plating on the same medium. Prototheca spp. cells were isolated from water samples by filtration through membranes (pore size $0.22 \mu \mathrm{m}$ ) and growth on PIM agar dishes, whereas isolation from bedding, feces, and feed was done through an enrichment procedure in liquid PIM and subsequent streaking on PIM agar dishes.

Strains of Prototheca spp. were isolated from PIM dishes and conserved at $-80^{\circ} \mathrm{C}$. Working cultures were grown on YEPG (yeast extract $10 \mathrm{~g} / \mathrm{L}$, peptone $10 \mathrm{~g} / \mathrm{L}$, glucose $20 \mathrm{~g} / \mathrm{L}$ ) agar slants and identified on the basis of the latest taxonomic guidelines (Pore, 1998).

Approximately $12 \%$ of glands were infected with viable cells of P. zopfii (11.7\% from herd A and 13.1\% from herd B), whereas other microorganisms were detected at percentages of approximately 1 to $2 \%$ (Table 
Table 2. Frequency of isolation of viable cells of Prototheca spp. and of other pathogenic microorganisms from milk samples

\begin{tabular}{lrrrrr}
\hline & \multicolumn{2}{c}{ Frequency of samples } & & \multicolumn{2}{c}{ SCC $\left(\times 10^{3}\right.$ cells $\left./ \mathrm{mL}\right)$} \\
\cline { 2 - 3 } \cline { 5 - 6 } Microorganism & $\mathrm{n}$ & $\%$ & & Mean & SD \\
\hline No growth & 385 & 70.2 & & 397.27 & $1,048.39$ \\
Prototheca spp. & 65 & 11.9 & & $1,364.63$ & $1,797.39$ \\
Staphylococcus aureus & 12 & 2.2 & & $1,169.83$ & $1,738.70$ \\
Escherichia coli & 8 & 1.5 & & 484.38 & 641.54 \\
Streptococcus uberis & 9 & 1.6 & & $3,082.89$ & $2,435.64$ \\
Streptococcus dysgalactiae & 6 & 1.1 & & $2,191.17$ & $2,249.93$ \\
CNS spp. & 8 & 1.5 & & 120.88 & 85.56 \\
Mixed presence & 55 & 10.0 & & 373.28 & $1,396.08$ \\
Total & 548 & 100 & & 589.33 & $1,337.29$ \\
\hline
\end{tabular}

2). For samples of environmental origin, $15 \%$ of fecal samples and approximately $33 \%$ of bedding samples were contaminated by $P$. zopfii (Table 3 ). These results are similar to previous observations by Costa et al. (1997), emphasizing the role of decaying organic matter (commonly found in the bedding of dairy herds) as a reservoir of viable cells of this microalga suspected to favor infection of the mammary glands (Pore, 1973, 1998).

No viable cells of $P$. zopfii were observed in water before washing of the milking system, whereas $28 \%$ of water samples collected after washing the milking equipment were contaminated by this microalga. Similarly, more than $40 \%$ samples from teat cup liners were found to be contaminated by $P$. zopfii only after milking procedures (Table 2). These observations were consistent with the current literature (McDonald et al., 1984; Furuoka et al., 1989; Janosi et al., 2001) and suggest that contaminated milking apparatus (teat cup liners, in particular) might favor a transfer of disease between infected and noninfected cows. Furthermore, the absence of Prototheca in the washing water and teat cup rubber samples collected before milking suggests that the cleaning operations of the milking apparatus were effective in removing this microalga from the milking apparatus in both herds. In light of this observation, the recommended prophylaxis based on separate milking (and possibly culling) of infected and noninfected cows, the use of effective premilking teat disinfectants, and the careful sanitation of milking apparatus appears to be fully justified.

The presence of $P$. zopfii in milk refrigeration tanks was confirmed both by the plate counts (from 10 to 100 $\mathrm{cfu} / \mathrm{mL}$ ) carried out on the refrigerated milk and by the isolation of viable cells of this microalga in water collected after washing procedures (25\% of samples contaminated; Table 3). Interestingly, in 1 of the 2 herds taken into consideration, water from the drinking trough was contaminated by viable cells of both $P$. zopfii and the related environmental species $P$. stagnora (Table 3), whereas no viable cells were observed in the cow feed.

The observed occurrence of $P$. zopfii strains in the herd environment seems to indicate that there is considerable potential for exposure of cows to the organism through contact with contaminated feces, teat cup lin-

Table 3. Frequency of isolation of viable cells of Prototheca spp. from different environmental sources in dairy herds A and B

\begin{tabular}{|c|c|c|c|c|c|}
\hline \multirow[b]{2}{*}{ Source } & \multicolumn{2}{|c|}{ Samples, n } & \multicolumn{2}{|c|}{$\begin{array}{l}\text { Samples positive to } \\
\text { Prototheca spp., } \mathrm{n}\end{array}$} & \multirow[b]{2}{*}{ Species } \\
\hline & Herd A & Herd B & Herd A & Herd B & \\
\hline Feces & 10 & 10 & 2 & 1 & P. zopfii \\
\hline Feed & 10 & 10 & 0 & 0 & \\
\hline Bedding & 6 & 6 & 3 & 1 & P. zopfii \\
\hline Washing water before milking & 1 & 4 & 0 & 0 & \\
\hline Water after washing the milking apparatus & 2 & 5 & 1 & 1 & P. zopfii \\
\hline Water after washing the refrigeration tank & 2 & 2 & 1 & 0 & P. zopfii \\
\hline \multirow[t]{3}{*}{ Water from the drinking trough } & 39 & 15 & & & \\
\hline & & & 3 & 0 & P. zopfii \\
\hline & & & 8 & 0 & P. stagnora \\
\hline Teat cup rubber before milking & 16 & 16 & 0 & 0 & \\
\hline Teat cup rubber after milking & 16 & 16 & 5 & 5 & P. zopfii \\
\hline Postdipping liquid & 3 & 2 & 0 & 0 & \\
\hline
\end{tabular}


ers, and water. Accordingly, all these factors might act as sources of $P$. zopfii in the dairy herds under study. Further investigation to clarify additional epidemiological features of $P$. zopfii infection is underway.

\section{REFERENCES}

Aalbaek, B., H. E. Jensen, and A. Huda. 1998. Identification of Prototheca from bovine mastitis in Denmark. Acta Pathol. Microbiol. Immunol. Scand. 106:483-488.

Almeraya, A. P. 1994. Aislamiento de Prototheca en um brote de mastitis bovina. Vet. Mexico 25:65-67.

Anderson, K. L., and R. L. Walker. 1988. Sources of Prototheca spp. in a dairy herd environment. J. Am. Vet. Med. Assoc. 193:553556.

Buzzini, P., B. Turchetti, R. Facelli, R. Baudino, F. Cavarero, L. Mattalia, P. Mosso, and A. Martini. 2004. First large-scale isolation of Prototheca zopfii from milk produced by dairy herds in Italy. Mycopathologia 158:427-430.

Casal, M., and J. Gutierrez. 1983. In vitro activity of ribostamycin against Prototheca spp. Mycopathologia 83:21-23.

Costa, E. O., P. A. Melville, A. R. Ribeiro, E. T. Watanabe, and M. C. F. F. Parolai. 1997. Epidemiologic study of environmental sources in a Prototheca zopfii outbreak of bovine mastitis. Mycopathologia 137:33-36.

de Vargas, A. C., A. Lazzari, J. M. Santurio, S. H. Alves, G. Ferreira, and L. C. Kreutz. 1998. Isolation of Prototheca zopfii from a case of bovine mastitis in Brazil. Mycopathologia 142:135-137.

Furuoka, H., A. Anri, Y. Arita, N. Tuzuki, H. Satoh, and C. Itakura. 1989. Protothecal mastitis in a cow. Jpn. J. Vet. Sci. 51:197199.
Higgins, R., and Y. Larouche. 1989. Isolation and identification of Prototheca, an agent of bovine mastitis. Med. Vet. Quebec 19:140-141.

Janosi, S., F. Ratz, G. Szigeti, M. Kulcsar, J. Kerenyi, T. Lauko, F. Katona, and G. Huszenicza. 2001. Review of the microbiological, pathological and clinical aspects of bovine mastitis caused by the alga Prototheca zopfii. Vet. Q. 23:58-61.

Legneau, P. E. 1996. First isolation of Prototheca zopfii in bovine mastitis in Belgium. J. Mycol. Med. 6:145-148.

McDonald, J. S., J. L. Richard, and N. F. Cheville. 1984. Natural and experimental bovine intramammary infections with Prototheca zopfii. Am. J. Vet. Res. 45:592-595.

National Mastitis Council. 1996. Current Concepts of Bovine Mastitis. 4th ed. Natl. Mastitis Counc., Madison, WI.

Pore, R. S. 1973. Selective medium for the isolation of Prototheca. Appl. Microbiol. 26:648-649.

Pore, R. S. 1998. Prototheca Krüger. Pages 883-887 in The Yeasts: A Taxonomic Study. Elsevier, New York, NY.

Pore, R. S., E. A. Barnett Jr., W. C. Barnes, and J. D. Walker. 1983. Prototheca ecology. Mycopathologia 81:49-62.

Segal, E., A. A. Padhye, and L. Ajello. 1976. Susceptibility of Prototheca species to antifungal agents. Antimicrob. Agents Chemother. 10:75-79.

Shahan, T. A., and R. S. Pore. 1991. In vitro susceptibility of Prototheca spp. to gentamicin. Antimicrob. Agents Chemother. 35:2434-2435.

Ueno, R., N. Urano, and M. Suzuki. 2003. Phylogeny of the non-photosynthetic green micro-algal genus Prototheca (Trebouxiophyceae, Chlorophyta) and related taxa inferred from SSU and LSU ribosomal DNA partial sequence data. Microbiol. Lett. 223:275-280. 